\title{
The Effect of Ramp Rate and Annealing Temperature on Boron Transient Diffusion in Implanted Silicon: Kinetic Monte Carlo Simulations
}

\author{
M.J. Caturla \\ M. Foad
}

T. Diaz de la Rubia

This paper was prepared for submittal to the

Ion Implantation Conference

Kyoto, Japan

June 21-24, 1998

June 17, 1998

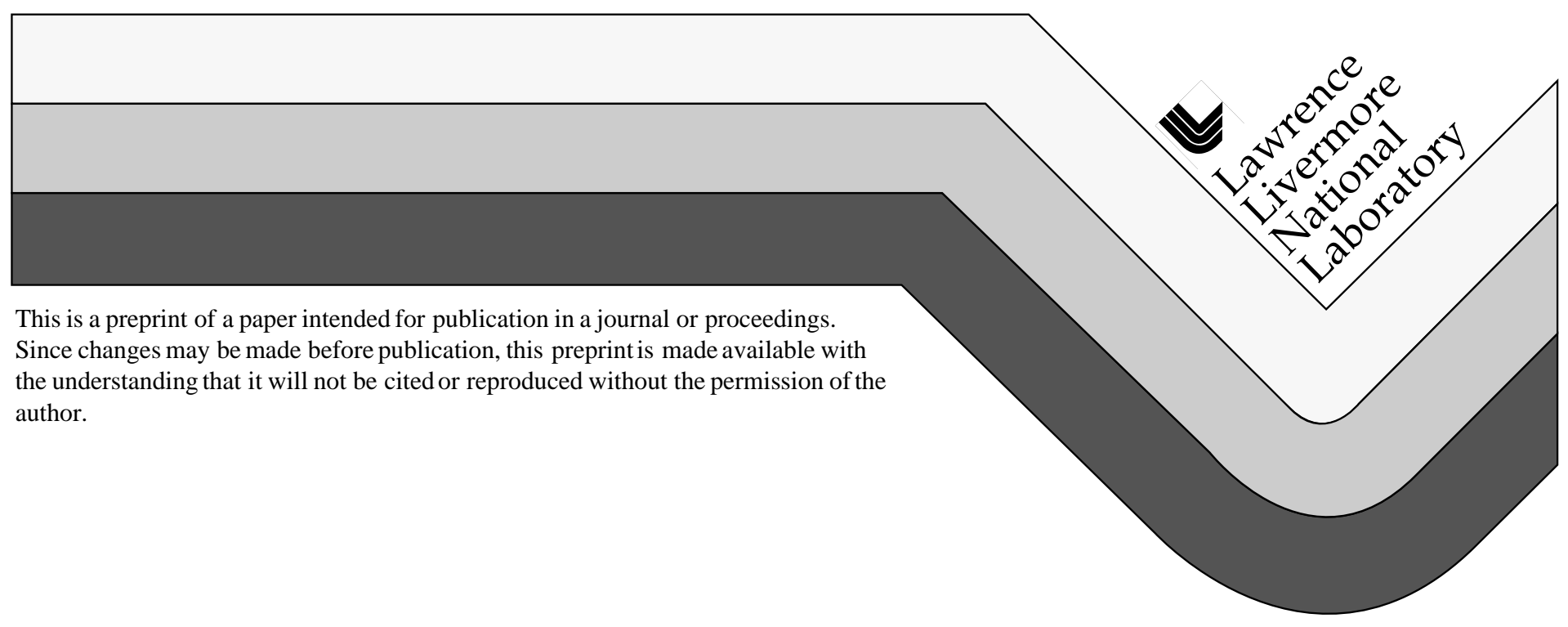




\section{DISCLAIMER}

This document was prepared as an account of work sponsored by an agency of the United States Government. Neither the United States Government nor the University of California nor any of their employees, makes any warranty, express or implied, or assumes any legal liability or responsibility for the accuracy, completeness, or usefulness of any information, apparatus, product, or process

disclosed, or represents that its use would not infringe privately owned rights. Reference herein to any specific commercial product, process, or service by trade name, trademark, manufacturer, or otherwise, does not necessarily constitute or imply its endorsement, recommendation, or favoring by the United States Government or the University of California. The views and opinions of authors expressed herein do not necessarily state or reflect those of the United States Government or the University of California, and shall not be used for advertising or product endorsement purposes. 


\title{
The effect of ramp rate and annealing temperature on Boron transient Diffusion in Implanted Silicon: kinetic Monte Carlo simulations
}

\author{
M.J. Caturla ${ }^{1}$, M. Foad ${ }^{2}$ and T. Diaz de la Rubia ${ }^{1}$ \\ 1. Lawrence Livermore National Laboratory, Livermore CA 94550 \\ 2. Applied Materials, Santa Clara, CA 95050
}

\begin{abstract}
We present results of recent kinetic Monte Carlo simulations of the effect of annealing time and ramp rate on boron transient enhanced diffusion (BTED) in low energy ion implanted silicon. The simulations use a database of defect and dopant energetics derived from first principle calculations. We discuss the complete atomistic details of defect and dopant clustering during the anneals, and the dependence of boron TED on ramp rate. The simulations proviede a complete time history of the evolution of the active boron fraction during the anneal for a wide variety of conditions. We also studied the lateral spreading of the boron during the annealing for two different conditions, furnace anneal and ramp anneal.
\end{abstract}

\section{Introduction}

As the device size shrinks it becomes more and more important to understand and quantify phenomena such as transient enhanced diffusion of dopants such as boron. Models that predict the behavior of boron during different annealing conditions are necessary to reduce the cost in the development of future devices. For these models to be predictive they must include all the physical phenomena underlying the macroscopic effect of enhanced Boron diffusivity. In particular, ultra shallow profiles [1] present many challenges for the construction of predictive models. Several issues must be investigated in order to understand all the processes occuring during the implantation and annealing of these very low energy implanted dopants, such as the interaction of the dopants with the surface. Moreover, in order to reduce the thermal budget for the production of such devices, new high temperature processes are being used [2]. These anneals consist, mostly, on the rapid increase of the temperature, with ramp rates from $75 \mathrm{C}$ per second, to as fast as $150 \mathrm{C} / \mathrm{s}$, to temperatures as high as 1050 C. This differs from the conventional furnace anneal during several minutes at medium temperatures, $800 \mathrm{C}$. In this paper we present a first approach to the understanding of the ramp rate on the activation of boron atoms. We use kinetic Monte Carlo simulations, following the approach by Heinisch to study radiation damage problems in metals [3]. This kinetic Monte Carlo simulation, uses as input parameters the migration energies of vacancies, interstitials and boron atoms, the binding energies of clusters of defects, both vacancies and interstitials and mixed clusters, such as those formed by boron atoms and silicon self-interstitials. The values for these energies have been extracted from a variety of simulations. The energetics for boron migration and for the binding energies of B-I clusters calculated by Zhu $[4,5]$ have been used in this simulation. The diffusivities and binding energies of small clusters used in the model were calculated by G. Gilmer [6] using molecular dynamics simulations with the Stillinger-Weber interatomic potential. The different energies for migration and binding set the rate for migration and dissociation of defects and 
clusters. Jump distances are set to first nearest neighbors. For more details on the simulation model see ref. [7, 8]. We simulate the implantation of $1 \mathrm{keV}$ Boron to a dose of $10^{14}$ ions $/ \mathrm{cm}^{2}$ into silicon using this model. The damage produced by the energetic particles were obtained using a binary collision model, UTMarlowe [9], proved to give accurate distribution profiles for energies as low as $1 \mathrm{keV}$ in the case of boron. Individual ions are included in the simulation box at a rate given by the dose rate, in this case $10^{12}$ ions $/ \mathrm{cm}^{2} / \mathrm{s}$.

Following the inplantation we have studied the evolution of the boron for different annealing conditions, the conventional furnace anneal at $800 \mathrm{C}$ for 30 minutes, and ramp anneals to a final temperature of $1050 \mathrm{C}$, with different ramp rates.

\section{Results}

After the final dose has been reached most of the Boron is forming cluster of the type BI (one boron and one silicon self-interstitial) or BI2 (one boron and two self-interstitials). Vacancies are forming small clusters (size 2 or 3 ) and interstitials are mostly single. Only $25 \%$ of the total implanted dose is active after the implantation. Fig 1 shows the evolution of the boron clusters for the annealing of the sample up to a temperature of $1050 \mathrm{C}$, with a temperature increase of $150 \mathrm{C}$ every second. On the right axis we present the concentration of boron in clusters as a function of time. As we mentioned earlier, after implantation most of the boron clusters are of the type $\mathrm{BI}$ and $\mathrm{BI} 2$. As the temperature increases bigger boron clusters grow, such as B3I. In the right axis of fig 1 we show the percentage of boron active during the annealing (solid line).

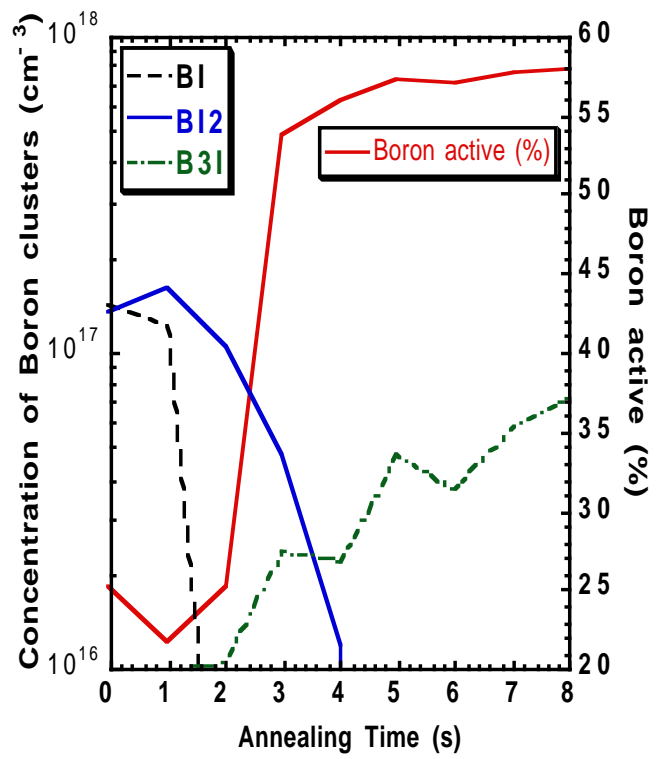

Fig 1. Evolution of the boron clusters during annealing from $27 \mathrm{C}$ to $1050 \mathrm{C}$ with temperature increase of $150 \mathrm{C}$ every second. The left axis shows the concentration of different boron clusters, $\mathrm{BI}, \mathrm{BI} 2$ and B3I. The right axis shows the percentage of Boron active in the sample during annealing.

After the implantation only $\sim 25 \%$ of the total implanted dose is active. After 2 seconds the amount of boron active increases rapidly until it reaches maximum value of $58 \%$ of the total implanted dose. We should point out that $\sim 30 \%$ of the implanted boron atoms accumulate at the surface. The interaction of the dopants with the surfaces needs to be investigated in more detail. 
(a)

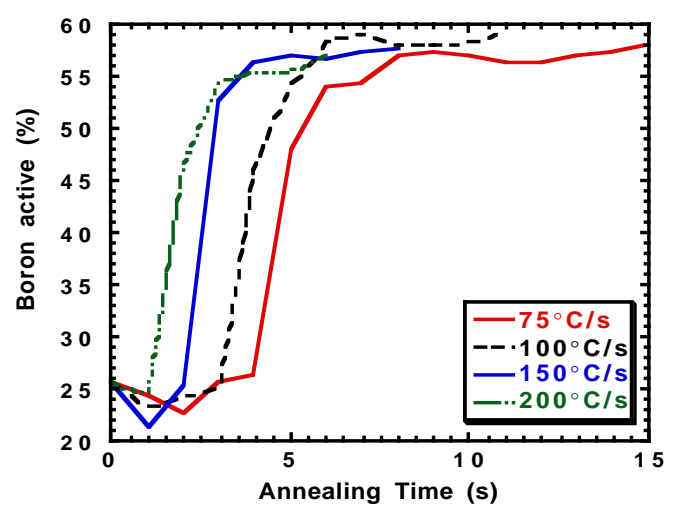

(b)

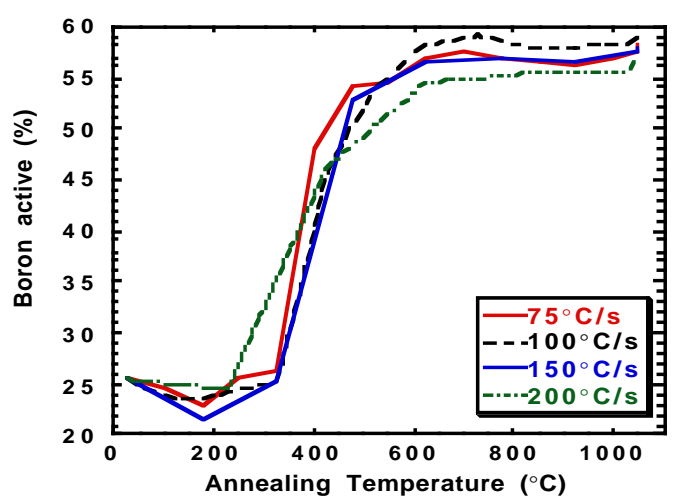

Fig 2. Percentage of boron active during annealing from $27 \mathrm{C}$ to $1050 \mathrm{C}$ of a $1 \mathrm{keV}$ B profile, $10^{14} \mathrm{ions} / \mathrm{cm}^{2}$ and for different ramp rates as a function of (a) annealing time and (b) annealing temperature.
We have done simulations for different ramp rates and the same final temperature, $1050 \mathrm{C}$. Ramp rates between $75 \mathrm{C} / \mathrm{s}$ and $200 \mathrm{C} / \mathrm{s}$ were considered in these simulations. In fig 2(a) we show the result values of the percentage of boron active during annealing for these ramp rates as a function of annealing time. Observe that, as expected, the maximum activation is observed at earlier times as the ramp rate increases. Fig 2(b) shows the percentage of active boron for the different ramp rates as a function of annealing temperature. Observe that for all cases the activation of boron occurs in a narrow temperature gap, between $350 \mathrm{C}$ and $600 \mathrm{C}$, independently of the different ramp rates. We can not extract any conclusions about the different total activations at the end of the anneal, since the differences observed are in the error of the calculation. As for the final boron concentration profile, no significant differences were observed in the simulations for all the different ramp rates studied.

We have simulated the furnace anneal of the $1 \mathrm{keV} \mathrm{B}$ profile for a temperature of $800 \mathrm{C}$ and a total time of 60 minutes. Fig 3 shows the concentration of the boron as a function of depth for the asimplanted profile, furnace anneal and anneal at a ramp of $150 \mathrm{C} / \mathrm{s}$ up to $1050 \mathrm{C}$. The larger broadening is observed for the case of furnace anneal. For a concentration of $1017 \mathrm{~cm}-3$, the profile broadens to a depth of $110 \mathrm{~nm}$ for the case of furnace anneal while only to $80 \mathrm{~nm}$ for the case of a ramp anneal. We also studied the lateral spreading of the implanted profile. For the case of furnace anneal $2.3 \%$ of the implanted boron diffused under the gate while only $0.9 \%$ of the implanted boron diffused in the ramp case.

We can conclude that ramp anneals provide of a larger activation of the boron than in the case of furnace anneals, with smaller boron enhanced diffusion. More simulations are on the way in order to study the effect of the ramp anneal on the final amount of boron active. 


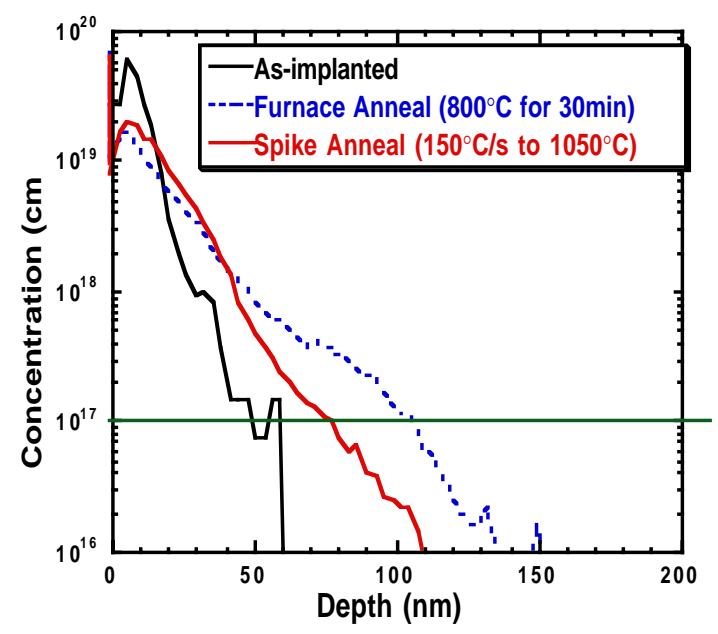

Fig 3. Boron concentration as a function of depth for as-implanted, $1 \mathrm{keV} \mathrm{B,} 10^{14}$ ions $/ \mathrm{cm}^{2}$, furnace anneal at $800 \mathrm{C}$ for 30 minutes, and a ramp anneal to a temperature of $1050 \mathrm{C}$, with temperature increase of $150 \mathrm{C}$ per second.

\section{References}

[1] M. Foad, J. England, S. Moffatt, D. Armour, Ion Implantation Tech. Austin, Tx, June 96

[2] P. Singer, Semicond. Internat. June $96,72-80$

[3] H. L. Heinisch, Nucl. Instrum. and Methods, B102, 47 (1995)

[4] J. Zhu, T. Diaz de la Rubia, C. Maihot, Phys. Rev. B54, 4741 (1996)

[5] J. Zhu, Mater. Res. Soc. Symp. Proc. 469. 151 (1997)

[6] G. Gilmer, T. Diaz de la Rubia, M. Jaraiz, Nucl. Instrum. and Methods B102, 257 (1995)

[7] M. D. Johnson., M. J. Caturla, T. Diaz de la Rubia., J. Appl. Phys. (in press)

[8] M. J. Caturla, M. D. Johnson, T. Diaz de la Rubia, Appl. Phys. Lett. (in press)

[9]. S. Tian, S. J. Morris, B. Obradovic, M. F. Morris, G. Wang, G. Balamurugan., A. F. Tasch, C. Snell, U.T, Marl;owe, Version 4.0 (1996)

\section{Acknowledgment}

This work was performed in part under the auspices of the US Department of Energy by Lawrence Livermore National Laboratory under contract W-7405-Eng48 